\title{
PERFIL NUTRICIONAL DE ALIMENTOS COM ALEGAÇÃO DE ZERO GORDURA TRANS
}

\author{
Ana Carolina Moron Gaglardi*1, Jorge Mancini Filho², Raul D. Santos ${ }^{3}$
}

Trabalho realizado no Instituto do Coração da Faculdade de Medicina da Universidade de São Paulo, São Paulo, SP

\section{*Correspondência:}

Incor

Av Dr Enéas de Carvalho

Aguiar, $44-2^{\circ}$ andar -

Bloco 2 - sala 4

CEP 05403-904

São Paulo - SP

anacarolg@usp.br

\begin{abstract}
RESUMO
OвJetıvo. Avaliar a composição de ácidos graxos de alguns alimentos industrializados disponíveis no mercado brasileiro nos quais houve redução da quantidade de ácidos graxos trans. Verificar também se estes alimentos atendem às quantidades recomendadas de consumo de gordura saturada, após redução de gordura trans.

Métodos. Alimentos industrializados (margarina cremosa A e B, margarina com fitosterol, biscoito doce recheado, biscoito salgado sem recheio, batata frita e lanche com hambúrguer de fast food multinacional com alegação de $0 \%$ de gordura trans foram adquiridos em pontos comerciais e analisados em cromatógrafo gasoso.

Resultados. Apesar da redução nas quantidades de ácidos graxos trans, os alimentos analisados contêm grandes quantidades de gorduras saturadas principalmente 0 ácido palmítico. Além disso, alguns dos alimentos estudados apresentam uma razão $n-3 / n-6$ fora do recomendado para a prevenção da aterosclerose.

Conclusião. $O$ consumo irrestrito desses alimentos tem forte potencial deletério para a saúde. $O$ rótulo de ausência de ácidos graxos trans deve ser visto com cuidado e não significa uma liberação para o consumo irrestrito desses alimentos.

Unitermos: Alimentos industrializados. Análise de alimentos. Ácidos graxos trans. Gorduras vegetais. Colesterol HDL. Colesterol LDL.
\end{abstract}

\section{INTRODUÇÃO}

O processo de hidrogenação parcial dos ácidos graxos polinsaturados é utilizado de forma abrangente na indústria alimentar e é o responsável pela geração da maior parte das gorduras trans consumidas atualmente $!$. O uso de gorduras parcialmente hidrogenadas acelerou-se a partir da década de 1960, em resposta às recomendações contra o consumo de gordura animal rica em gorduras saturadas e colesterol, devido aos efeitos deletérios destes sobre o perfil lipídico e o risco de aterosclerose. Os ácidos graxos parcialmente hidrogenados seriam uma boa alternativa para indústria de alimentos devido a sua estabilidade, baixo custo, disponibilidade e funcionalidade! No entanto, uma importante publicaçãa ${ }^{2}$ comparando efeitos de dietas ricas em ácido oléico, ácidos graxos saturados e trans no perfil lipídico de pacientes mostrou claros efeitos deletérios dos ácidos graxos trans sobre o perfil lipídico.

Recentemente, Mozaffarian et al. ${ }^{3}$ demonstraram que um aumento de $2 \%$ na energia consumida como ácidos graxos trans associa-se de forma inequívoca a um aumento de $23 \%$ na incidência de doença arterial coronária.

A partir dos resultados obtidos nas avaliações epidemiológicas e experimentais, relacionando os ácidos graxos trans com alterações metabólicas do organismo, entidades governamentais de vários países, incluindo o Brasil, sugeriram diminuição no consumo deste tipo de gordura e legislaram que estes ácidos graxos devem ter sua quantidade informada no rótulo dos alimentos. Consequentemente, muitas indústrias e cadeias de restaurantes vêm retirando ou minimizando a quantidade de ácidos graxos trans dos seus produtos e usando a alegação 0\% de gordura trans como uma medida boa para saúde. No entanto, dados clínicos e epidemiológicos indicam que além do baixo teor de gorduras trans, é importante também que os alimentos tenham pequenas quantidades de gorduras saturadas e uma boa relação dos ácidos graxos polinsaturados ômega 3 (n-3) e ômega 6 (n-6).

Tecnicamente, reformulações de gorduras que excluem ácidos graxos trans e ao mesmo tempo preservem estrutura, palatabilidade e minimizem efeitos indesejáveis à saúde exigem muitas vezes aumento de custo, modificações importantes na indústria e nas formulações ${ }^{4}$. Um grande número de tecnologias tem sido desenvolvido para minimizar a quantidade de ácidos graxos trans nos óleos alimentares e alimentos4.

O óleo de palma é uma alternativa aceitável para a indústria por preservar características de palatabilidade e conservação dos alimentos. Contudo do ponto de vista nutricional óleos vegetais não-hidrogenados (ex: soja, canola, milho, girassol) produzem melhores efeitos no perfil lipídico, se comparados ao óleo de palma ou a óleos hidrogenados, e estes é que devem ser os preferidos ${ }^{5}$. Uma metanálise de 60 estudos

1. Doutoranda em cardiologia no Instituto do Coração da Faculdade de Medicina da Universidade de São Paulo. São Paulo, SP, Brasil

2. Professor Titular da Faculdade de Ciências Farmacêuticas da USP. São Paulo, SP, Brasil

3. Professor Livre Docente da Faculdade de Medicina da Universidade de São Paulo - Diretor da Unidade Clínica de Lípides do Instituto do Coração - InCor HCFMUSP. São Paulo, SP, Brasil. 
controlados mostra que em comparação com os ácidos graxos trans há pouca ou nenhuma diferença do consumo de ácido palmítico em relação às concentrações do LDL-colesterol. Por outro lado, este aumenta as concentrações de HDL-colesterol e a razão colesterol total/ HDL e a concentração de triglicérides são modificadas mais favoravelmente quando comparadas aos trans ${ }^{5}$. Contrariamente, quando há substituição dos ácidos graxos trans por ácidos graxos polinsaturados ou monoinsaturados ocorre diminuição da razão colesterol total/HDL, fato que diminuiria o risco de eventos cardiovasculares. Contudo, o impacto dessas mudanças merece ser avaliado de forma prospectiva e controlada.

Uma alternativa acessível é o uso de óleos e gorduras ricos em ácido esteárico (para gorduras sólidas) ou ácido oléico (para óleos líquidos) que promovem funcionalidade apropriada sem hidrogenação ${ }^{6}$. $O$ ácido esteárico apesar de saturado tem discretos efeitos sobre 0 LDL-colesterol, pois é metabolizado em ácido oléico pelo organismo. Em estudo recente ${ }^{7}$, não encontraram diferenças no perfil lipídico (HDL-colesterol e triglicérides) quando compararam consumo de dietas enriquecidas com ácido esteárico, oléico e linoléico. Houve apenas uma pequena diferença na concentração de LDL-colesterol com tendência à diminuição com o aumento do grau de insaturação.

O efeito da potencial mudança no perfil de ácidos graxos de produtos que não mais possuem ácidos graxos trans necessita ser avaliado, principalmente porque gorduras saturadas têm sido utilizadas como seus substitutos.

O objetivo deste estudo foi avaliar a composição de ácidos graxos de alguns alimentos disponíveis no mercado brasileiro, nos quais houve redução da quantidade de ácidos graxos trans. Avaliou-se também se estes alimentos atendem às quantidades recomendadas de consumo de gordura saturada após redução de gordura trans.

\section{Métodos}

Alimentos industrializados (margarina cremosa $\mathrm{A}$ e $\mathrm{B}$, margarina com fitosterol, biscoito doce recheado, biscoito salgado sem recheio, batata frita e lanche com hambúrguer cadeia de fast food multinacional com alegação de $0 \%$ de gordura trans foram adquiridos em pontos comerciais e analisados em cromatógrafo gasoso no dia da compra para evitar oxidação ou deterioração no produto. Outros produtos também foram analisados para comparação: manteiga (rica em gordura saturada) e margarina dura (com ácido graxo trans).

As análises foram realizadas no laboratório de lípides da Faculdade de Ciências Farmacêuticas da Universidade de São Paulo. Para as análises dos produtos foi feita extração da gordura e esterificação, por método padronizado ${ }^{8}$, e posterior injeção em cromatógrafo a gás GC 17 A Shimadzu/ Class GC 10 (Shimadzu Corporation, Japan) nas seguintes condições: coluna cromatográfica de sílica fundida SP-2560 (biscianopropil polisiloxana) de $100 \mathrm{~m}$ e $0.25 \mathrm{~mm}$ de d.i., temperatura da coluna isotérmica a $180^{\circ} \mathrm{C}$ por 75 min.; temperatura do vaporizador: $250^{\circ} \mathrm{C}$; temperatura de detector: $260^{\circ} \mathrm{C}$; gás de arraste: Hélio (I ml/min.) e razão de divisão da amostra no injetor $=1 / 200$.

As análises foram feitas em triplicata, sendo calculada a média e desvio padrão das amostras. Os resultados foram expressos em grama do ácido graxo / 100 gramas de amostra e baseados nos teores de gordura encontrados nas amostras, utilizando-se fatores de correção?.
Foi efetuado o cálculo da porcentagem de ácidos graxos encontrados nos alimentos baseados nas recomendações de consumo das IV Diretriz Brasileira de Dislipidemia e Prevenção de Aterosclerose ${ }^{10}$. Foi calculada também a razão ômega3/ ômega6 dos alimentos.

\section{Resultados}

A Tabela I mostra a composição percentual de ácidos graxos dos alimentos estudados. Todos os produtos analisados, com exceção do biscoito doce recheado, têm quantidade maior ou igual a 50\% de gordura saturada proveniente de ácido palmítico. Maiores quantidades deste ácido graxo foram encontradas em ordem decrescente na manteiga, margarina cremosa A, margarina dura, biscoito doce recheado e biscoito salgado. Os outros ácidos graxos saturados encontrados foram láurico, mirístico e esteárico. O ácido esteárico esteve presente em maior quantidade também na manteiga, seguido de margarina dura e menor quantidade na batata frita. Em geral, foi encontrada uma concentração duas vezes maior de ácido palmítico em relação ao ácido esteárico.

O ácido linoléico ( $n-6)$ esteve presente em maior quantidade na margarina cremosa $A$, seguido da margarina cremosa $B$, margarina com fitosterol e margarina dura e em menores quantidades no lanche de fast food e biscoito doce recheado. Já o ácido alfa linolênico (n-3) foi encontrado em maior porcentagem na margarina cremosa $B$, margarina com fitosterol e margarina dura e menores quantidades nos outros alimentos. A relação n-6/n-3 na batata frita de fast food e nos biscoitos recheado e salgado foram, respectivamente, 70/I, 90/I e 90/I, bem acima do recomendado pela FAO-WHO". Nos outros alimentos, a relaçãa variou de $4 / I$ a I0/I dentro da faixa de recomendação".

Foram encontradas pequenas quantidades de ácidos graxos trans nos alimentos, com exceção da margarina dura e da manteiga, confirmando a retirada deste ácido graxo dos alimentos. A Tabela 2 mostra o perfil de ácidos graxos por porção de alimento servida.

A Tabela 3 mostra a adequação de gorduras saturadas em relação à recomendação, com base na quantidade máxima estipulada pela IV Diretriz Brasileira de Dislipidemias e Prevenção da Aterosclerose ${ }^{10}$, de $7 \%$ do valor calórico total consumido no dia. Em ordem decrescente de quantidade de gorduras saturadas temos: lanche de hambúrguer com batata frita, hambúrguer, batata frita, biscoito recheado, biscoito salgado e margarina.

\section{Discussão}

Nosso estudo mostra que, apesar da redução nas quantidades de ácidos graxos trans, os alimentos analisados contêm grandes quantidades de gorduras saturadas principalmente o ácido palmítico. Além disso, alguns dos alimentos estudados apresentam uma razão n-6/n-3 fora do recomendado para a prevenção da aterosclerose. Esses achados poderiam diminuir os possíveis benefícios da remoção da gordura trans nos alimentos estudados.

O óleo de palma é uma fonte rica em ácido palmítico e é utilizado mundialmente para preparo de alimentos industrializados e para frituras em cadeias de restaurantes de fast food. Este contém $45 \%$ de sua composição sob a forma de ácido palmítico fato que justifica as altas concentrações desse lípide nos alimentos estudados. Além disso, o óleo 


\begin{tabular}{|c|c|c|c|c|c|c|c|c|c|}
\hline \multicolumn{10}{|c|}{ Tabela I- Quantidade dos principais ácido graxo em produtos comerciais, em g/ $100 \mathrm{~g}$ de produto } \\
\hline $\begin{array}{l}\text { Ácido graxo/ } \\
\text { produto }\end{array}$ & Manteiga & $\begin{array}{l}\text { Margarina } \\
\text { dura }\end{array}$ & $\begin{array}{l}\text { Margarina } \\
\text { cremosa A }\end{array}$ & $\begin{array}{l}\text { Margarina } \\
\text { cremosa B }\end{array}$ & $\begin{array}{c}\text { Margarina } \\
\text { com fitosterol }\end{array}$ & $\begin{array}{l}\text { Biscoito doce } \\
\text { recheado }\end{array}$ & $\begin{array}{c}\text { Biscoito salgado } \\
\text { sem recheio }\end{array}$ & $\begin{array}{l}\text { Lanche de } \\
\text { fast food }\end{array}$ & $\begin{array}{l}\text { Batata frita de } \\
\text { fast food }\end{array}$ \\
\hline 12:0 láunco & $2,5 \pm 0,02$ & 0,0 & $1,5 \pm 0,12$ & $0,08 \pm 0,0$ & $0,98 \pm 0,01$ & $0,03 \pm 0,0$ & $0,04 \pm 0,0$ & $0,05 \pm 0,0$ & $0,02 \pm 0,0$ \\
\hline 14:0 mirístico & $9,2 \pm 0,08$ & $0,1 \pm 0,0$ & $0,9 \pm 0,0$ & $0,33 \pm 0,02$ & $0,39 \pm 0,01$ & $0,17 \pm 0,0$ & $0,15 \pm 0,0$ & $0,41 \pm 0,03$ & $0,08 \pm 0,0$ \\
\hline 16:0 palmítico & $24,6 \pm 0,23$ & $7,9 \pm 0,02$ & $10,4 \pm 0,03$ & $3,96 \pm 0,03$ & $3,74 \pm 0,0$ & $7,9 \pm 0,05$ & $6,88 \pm 0,09$ & $2,56 \pm 0,18$ & $2,74 \pm 0,06$ \\
\hline 18:0 esteárico & $10,6 \pm 0,08$ & $7,5 \pm 0,1$ & $6,0 \pm 0,02$ & $2,54 \pm 0,02$ & $2,7 \pm 0,0$ & $|, 97 \pm 0,0|$ & $1,0 \pm 0,0 \mid$ & $1,53 \pm 0,11$ & $0,75 \pm 0,01$ \\
\hline |8:1 oléico & $19,5 \pm 0,18$ & $17,0 \pm 0,47$ & $|6| \pm 0,04$, & $7,02 \pm 0,01$ & $7,1 \pm 0,02$ & $7,43 \pm 0,05$ & $6,15 \pm 0,08$ & $4, I \pm 0,3$ & $6,16 \pm 0,0$ \\
\hline 18:2 linoléico & $1,2 \pm 0,0$ & $12,7 \pm 0,03$ & $27,5 \pm 0,04$ & $16,4 \pm 0,07$ & $16,3 \pm 0,02$ & $2,7 \pm 0,02$ & $7, \mid 5 \pm 0,01$ & $2,01 \pm 0,1$ & $7,03 \pm 0,14$ \\
\hline |8:3 $\alpha$-linolênico & $0,3 \pm 0,02$ & $1,2 \pm 0,0$ & $3,1 \pm 0,0$ & $|, 75 \pm 0,0|$ & $|, 5 \pm 0,0|$ & $0,03 \pm 0,0$ & $0,08 \pm 0,1$ & $0,23 \pm 0,0$ & $0,1 \pm 0,0$ \\
\hline |8:It eládico & $3,5 \pm 0,03$ & $18,9 \pm 0,13$ & $0,1 \pm 0,0$ & $0,04 \pm 0,0$ & $0,17 \pm 0,01$ & $0,1 \pm 0,0$ & $0,31 \pm 0,0$ & $0,31 \pm 0,0$ & $0,02 \pm 0,0$ \\
\hline 18:2t linoleladico & $0,4 \pm 0,10$ & $0,8 \pm 0,01$ & $0,1 \pm 0,0$ & $0,1 \pm 0,0$ & $0,10 \pm 0,0$ & $0,13 \pm 0,0$ & $0,12 \pm 0,0$ & $0,10 \pm 0,0$ & $0,12 \pm 0,0$ \\
\hline Total saturada & $3,9 \pm 0,12$ & $19,7 \pm 0,1$ & $0,2 \pm 0,0$ & $0,1 \pm 0,0$ & $0,3 \pm 0,01$ & $0,2 \pm 0,0$ & $0,4 \pm 0,0$ & $0,4 \pm 0,04$ & $0,13 \pm 0,0$ \\
\hline Total monoinsaturada & $19,7 \pm 0,18$ & $|7| \pm 0,4$, & $16,4 \pm 0,04$ & $7,1 \pm 0,0$ & $7, I \pm 0,02$ & $7,5 \pm 0,05$ & $6,3 \pm 0,08$ & $4,6 \pm 0,3$ & $6,24 \pm 0,1$ \\
\hline Total polinsaturada & $1,5 \pm 0,0$ & $13,9 \pm 0,03$ & $30,7 \pm 0,05$ & $18,2 \pm 0,07$ & $17,8 \pm 0,01$ & $2,87 \pm 0,02$ & $7,2 \pm 0,1$ & $2,3 \pm 0,12$ & $7,12 \pm 0,14$ \\
\hline Razão n-6/n-3 & $4: 1$ & $10: 1$ & $8: 1$ & $8: 1$ & $10: 1$ & $90: 1$ & $90: 1$ & $8: 1$ & $70: 1$ \\
\hline
\end{tabular}

\begin{tabular}{|c|c|c|c|c|c|c|c|c|c|}
\hline $\begin{array}{l}\text { Ácido graxo/ } \\
\text { produto }\end{array}$ & $\begin{array}{l}\text { Manteiga } \\
14 \mathrm{~g}-2 \mathrm{e}^{1 / 2} \\
\text { colheres } \\
\text { sopa }\end{array}$ & $\begin{array}{c}\text { Margarina } \\
\text { dura } 10 \mathrm{~g} \text { - } \\
\text { I colher } \\
\text { sopa }\end{array}$ & $\begin{array}{l}\text { Margarina } \\
\text { cremosa } \\
\text { A log - } \\
\text { I colher sopa }\end{array}$ & $\begin{array}{l}\text { Margarina } \\
\text { cremosa } \\
\text { B IOg - } \\
\text { I colher sopa }\end{array}$ & $\begin{array}{c}\text { Margarina } \\
\text { com fitosterol } \\
\text { log - I colher } \\
\text { sopa }\end{array}$ & $\begin{array}{c}\text { Biscoito } \\
\text { doce recheado } \\
\text { 30g - } \\
3 \text { unidades }\end{array}$ & $\begin{array}{l}\text { Biscoito } \\
\text { salgado sem } \\
\text { recheio } 26 \mathrm{~g} \text { - } \\
\text { Ipacote }\end{array}$ & $\begin{array}{l}\text { Lanche de } \\
\text { fast food } \\
200 \mathrm{~g} \text { - } \\
\text { I unidade }\end{array}$ & $\begin{array}{l}\text { Batata frita } \\
\text { de fast } \\
\text { food } 102 \mathrm{~g} \text { - } \\
\text { I porção média }\end{array}$ \\
\hline 12:0 láurico & $0,35 \pm 0,02$ & 0,0 & $0,15 \pm 0,12$ & $0,00 \pm 0,0$ & $0,09 \pm 0,01$ & $0,0 \pm 0,0$ & $0,01 \pm 0,0$ & $0,10 \pm 0,0$ & $0,02 \pm 0,0$ \\
\hline 14:0 miŕśtico & $1,29 \pm 0,08$ & $0,014 \pm 0,0$ & $0,09 \pm 0,0$ & $0,03 \pm 0,02$ & $0,04 \pm 0,01$ & $0,05 \pm 0,0$ & $0,04 \pm 0,0$ & $0,81 \pm 0,03$ & $0,08 \pm 0,0$ \\
\hline |6:0 palmítico & $3,44 \pm 0,23$ & $0,79 \pm 0,02$ & $1,04 \pm 0,03$ & $0,39 \pm 0,03$ & $0,37 \pm 0,0$ & $0,59 \pm 0,05$ & $1,78 \pm 0,09$ & $5,12 \pm 0,18$ & $2,79 \pm 0,06$ \\
\hline 18:0 esteánico & $1,48 \pm 0,08$ & $0,75 \pm 0,1$ & $0,60 \pm 0,02$ & $0,25 \pm 0,02$ & $0,27 \pm 0,0$ & $0,59 \pm 0,01$ & $0,26 \pm 0,01$ & $3,06 \pm 0,11$ & $0,76 \pm 0,01$ \\
\hline |8:1 oléico & $2,73 \pm 0,18$ & $1,70 \pm 0,47$ & $1,61 \pm 0,04$ & $0,70 \pm 0,01$ & $0,71 \pm 0,02$ & $2,23 \pm 0,05$ & $1,6 \pm 0,08$ & $8,19 \pm 0,3$ & $6,28 \pm 0,0$ \\
\hline 18:2 linoleico & $0,16 \pm 0,0$ & $1,27 \pm 0,03$ & $2,75 \pm 0,04$ & $1,64 \pm 0,07$ & $1,63 \pm 0,02$ & $0,81 \pm 0,02$ & $1,86 \pm 0,01$ & $4,02 \pm 0,1$ & $7,17 \pm 0,14$ \\
\hline 18:3 $\alpha$-linolênico & $0,05 \pm 0,02$ & $0,12 \pm 0,0$ & $0,31 \pm 0,0$ & $0,17 \pm 0,01$ & $0,15 \pm 0,01$ & $0,01 \pm 0,0$ & $0,02 \pm 0,1$ & $0,46 \pm 0,0$ & $0,1 \pm 0,0$ \\
\hline |8: It eládico & $0,49 \pm 0,03$ & $1,89 \pm 0,13$ & $0,01 \pm 0,0$ & $0,00 \pm 0,0$ & $0,02 \pm 0,01$ & $0,03 \pm 0,0$ & $0,08 \pm 0,0$ & $0,62 \pm 0,0$ & $0,02 \pm 0,0$ \\
\hline 18:2t linoleladico & $0,05 \pm 0,10$ & $0,08 \pm 0,01$ & $0,01 \pm 0,0$ & $0,00 \pm 0,0$ & $0,01 \pm 0,0$ & $0,04 \pm 0,0$ & $0,03 \pm 0,0$ & $0,20 \pm 0,0$ & $0,12 \pm 0,0$ \\
\hline Total saturada & $7,22 \pm 0,45$ & $1,61 \pm 0,02$ & $1,98 \pm, 08$ & $0,79 \pm 0,08$ & $0,82 \pm 0,01$ & $3,09 \pm 0,06$ & $2,15 \pm 0,1$ & $9,7 \pm 0,35$ & $3,81 \pm 0,07$ \\
\hline Total moninsturada & $2,76 \pm 0,18$ & $|, 7| \pm 0,4$ & $1,64 \pm 0,04$ & $0,71 \pm 0,0$ & $0,71 \pm 0,02$ & $2,25 \pm 0,05$ & $1,64 \pm 0,08$ & $9,16 \pm 0,3$ & $6,36 \pm 0,1$ \\
\hline Total polinsaturada & $0,21 \pm 0,0$ & $1,39 \pm 0,03$ & $3,07 \pm 0,05$ & $1,82 \pm 0,07$ & $|, 78 \pm 0,0|$ & $0,86 \pm 0,02$ & $1,87 \pm 0,1$ & $4,55 \pm 0,12$ & $7,26 \pm 0,14$ \\
\hline Total trans & $0,54 \pm 0,12$ & $1,97 \pm 0,1$ & $0,02 \pm 0,0$ & $0,01 \pm 0,0$ & $0,03 \pm 0,01$ & $0,06 \pm 0,0$ & $0,1 \pm 0,0$ & $0,81 \pm 0,04$ & $0,13 \pm 0,0$ \\
\hline
\end{tabular}

\section{Tabela 3 - Adequação dos alimentos em relação à} recomendação de gordura saturada diária

\begin{tabular}{|c|c|c|c|c|c|c|}
\hline $\begin{array}{l}\text { Valor calórico total } \\
\text { consumo/ alimento }\end{array}$ & $\begin{array}{l}1000 \\
\text { Kcal }\end{array}$ & $\begin{array}{l}1200 \\
\text { Kcal }\end{array}$ & $\begin{array}{l}1600 \\
\text { Kcal }\end{array}$ & $\begin{array}{l}1800 \\
\text { Kcal }\end{array}$ & $\begin{array}{l}2000 \\
\text { Kcal }\end{array}$ & $\begin{array}{l}2500 \\
\text { Kcal }\end{array}$ \\
\hline Recomendação & $7,7 \mathrm{~g}$ & $9,3 \mathrm{~g}$ & $12,4 \mathrm{~g}$ & $14,0 \mathrm{~g}$ & $15,5 \mathrm{~g}$ & $\overline{19,4 \mathrm{~g}}$ \\
\hline Lanche hambúrguer & $>100 \%$ & $100 \%$ & $78 \%$ & $70 \%$ & & $50 \%$ \\
\hline tata & $50 \%$ & $40 \%$ & $30 \%$ & $27 \%$ & $26 \%$ & $.0 \%$ \\
\hline nche + batata & $>100 \%$ & $>100 \%$ & $95 \%$ & $85 \%$ & $83 \%$ & $61 \%$ \\
\hline coto recheado doce & $40 \%$ & $33 \%$ & $25 \%$ & $22 \%$ & $21 \%$ & $16 \%$ \\
\hline & $28 \%$ & & $17 \%$ & $15 \%$ & $15 \%$ & $1 \%$ \\
\hline Margarina cremosa & $25 \%$ & $21 \%$ & $16 \%$ & $14 \%$ & $13,7 \%$ & $10 \%$ \\
\hline
\end{tabular}

de palma apresenta uma relação $n 3 / n 6$ de $16 / 1$, que está além da recomendada pela OMS que é de $5-10 / I^{12}$. Dos alimentos estudados, o biscoito doce recheado, biscoito salgado e batata frita tiveram esta relação muito alta, variando de 70:I a 90: I, este desbalanço tem efeitos desfavoráveis à saúde ${ }^{12}$. Na manteiga, a relação foi menor que a recomendada (4:I), e nos outros alimentos a relação variou de 8:I a I0: I, estando dentro da faixa recomendada.

Nos alimentos estudados foi encontrada grande quantidade de gordura saturada, sendo que o consumo de lanche com hambúrguer por crianças ou pessoas com ingestão de até $1200 \mathrm{Kcal} /$ dia ultrapassa a recomendação diária para este tipo de gordura. Se o lanche com hambúrguer for consumido juntamente com a batata frita de fast food, 
pessoas com dieta de até $1600 \mathrm{Kcal}$ atingem o limite diário recomendado, pois este contém em média $505 \mathrm{Kcal}$ e quando associado à batata frita, fato frequente nos restaurantes de fast food, chega a $713 \mathrm{Kcal}$.

Nos biscoitos estudados, que são considerados apenas petiscos ou complementos alimentares, a quantidade de gordura saturada encontrada foi alta ( $11 \%$ a $40 \%$ da recomendação para todas faixas de calorias). O mesmo problema foi verificado na margarina, em que o consumo de uma colher de sopa é responsável por $25 \%$ da quantidade de gordura saturada que deveria ser consumida para crianças ou pessoas com ingestão baixa de calorias.

O problema do consumo frequente destes alimentos é que normalmente não são consumidos como única fonte de gordura saturada do dia, existindo grande probabilidade de ingestão exagerada desta gordura, o que pode ocasionar em alterações desfavoráveis no perfil lipídico plasmático.

Além da alta quantidade de gordura saturada, pode-se observar a grande densidade calórica dos alimentos estudados. A ingestão aumentada de calorias pode acarretar em obesidade, hipertensão, dislipidemia, resistência insulínica e diabetes tipo 2, que são importantes fatores de risco para doença cardiovascular ${ }^{13}$. Portanto, além de verificar a quantidade e o perfil de ácidos graxos dos produtos, atenção deve ser dada a sua quantidade calórica.

\section{Limitações do estudo}

Nosso estudo avaliou um número limitado de produtos, além disso não foi feita comparação de outras marcas nem dos efeitos dos mesmos sobre o perfil lipídico e sobre o risco de doença cardiovascular. Contudo as marcas avaliadas são de grandes empresas com forte controle de qualidade em relação à composição dos alimentos. Dessa forma, acreditamos que sua composição seja confiável e que os alimentos avaliados não devam ser consumidos fora das recomendações de gorduras e calorias.

\section{Conclusão}

Apesar da virtual ausência de gorduras trans foi encontrada grandes concentrações de gordura saturada, principalmente ácido palmítico nos alimentos avaliados. O consumo irrestrito desses alimentos tem forte potencial deletério para a saúde. O rótulo de ausência de ácidos graxos trans deve ser visto com cuidado e não significa uma liberação para o consumo irrestrito desses alimentos.

\section{Conflito de interesse: não há}

\section{SUMMARY}

\section{NUtRITIONAL PROFILE OF FOODS WITH ZERO TRANS FATTY ACIDS CLAIM}

OBIECTNE. To evaluate the composition of fatty acids in some foods available in the Brazilian market in which there was a claimed reduction in the amount of trans fatty acids. Also evaluate whether these foods meet recommended amounts for saturated fat consumption, after reduction of trans fat amounts.

Methods. Industrialized food (creamy margarine $A$ and B, plant sterol margarine, stuffed sweet biscuit, salty biscuit without stuffing,
French fried potatoes and a burger lunch from a multinational chain of "fast food" all with the allegation of $0 \%$ trans fat content were purchased in commercial points and analyzed by gas chromatography.

RESULTS. Despite the reduction in trans fatty acid amounts, analyzed foods contained large concentrations of saturated fats mainly palmitic acid. Moreover, some of the foods studied showed a n-6/n-3 ratio outside the recommended for atherosclerosis prevention.

CONCLUSION. The unrestricted consumption of such foods has strong deleterious health potential. The absence of trans fatty acid label should be viewed with caution and does not mean a release for unrestricted consumption of such foods. [Rev Assoc Med Bras 2009; 55(I): 50-3]

KEY wORDS: Industrialized foods. Food analysis. Trans fatty acids. Vegetable fats. Cholesterol HDL. Cholesterol LDL.

\section{REFERÊNCIAS}

I. Eckel RH, Borra S, Lichtenstein AH, Yin-Piazza SY. Understanding the complexity of trans fatty acid reduction in the American diet. American Heart Association trans fat conference 2006 report of trans fat conference planning group. Circulation. 2007; I I 5:223 I-46.

2. Mensink RP, Katan MB. Effect of dietary trans fatty acids on high-density and low-density lipoprotein cholesterol levels in healthy subjects. N Engl J Med. 1990; 323:439-45.

3. Mozaffarian D, Katan MB, Ascherio A, Stampfer MJ, Willett. Trans fatty acids and cardiovascular disease. N Engl J Med. 2006;354: I60 I - I3.

4. Tarrago-Trani MT, Phillips KM, Lemar LE, Holden JM. New and existing oils fats used in products with reduced trans-fatty acid content. J Am Diet Assoc. 2003; 106:867-80.

5. Mensink RP, Zock PL, Kester ADM, Katan MB. Effects of dietary fatty acids and carbohydrates on ratio of serum total to HDL cholesterol and on serum lipids and apolipoproteins; a metanalysis of 60 controlled trials. Am J Clin Nutr. 2003;77: I |46-55.

6. Liu Q, Sigh S, Green A. High-oleic and high-stearic cottonsed oils: nutritionally improved cooking oils developed using gene silencing. J Am Coll Nutr. 2002;21:205s-IIs.

7. Thijsen MA, Mensink RP. Small differences in the effects of stearic acid, olic acid, and linoleic acid on the serum lipoprotein profile of humans. Am J Clin Nutr. 2005;82:5 I 0-6.

8. Association of Official Analytical Chemists. Official methods of analysis. Arlington: Official Method; 2002. n. 996.06, cap. 4I. p.20.

9. Holland B, Welch A, Unwin ID, Buss DH, Paul AA, Southgate DAT. The composition of foods. Cambridge: Mc Cance and Widdowson's; 1994. p.8-9.

10. IV Diretriz Brasileira Sobre Dislipidemias e Prevenção da Aterosclerose. Departamento de Aterosclerose da Sociedade Brasileira de Cardiologia. Arquivos Brasileiros de Cardiologia. 2007; 88: I- 19.

I I. FAOMHO (Food and Agricultural Organization. Sociedade Brasileira de Cardiologia. Arquivos Brasileiros de Cardiologia. 2 Morld Health Organization). 1994. General conclusions and recommendations of the consultation. In: Fats and Oils in Human Nutrition. Rome: FAO; 2004. p.3-7.

12. Dietary Reference Intakes for Energy, Carbohydrate, fiber, fat, fatty acids, cholesterol, protein, and amino acids. Washington (DC): The national academies press 500 Fifth Street; 2001 .

13. Okie S. New York to trans fats: youre out! N Engl J Med. 2007;356:2017-21.

Artigo recebido: 24/10/07

Aceito para publicação: 20/04/08 